\title{
Visual-auditory interaction in speeded classification: Role of stimulus difference
}

\author{
ELISHEVA BEN-ARTZI and LAWRENCE E. MARKS \\ John B. Pierce Laboratory and Yale University, New Haven, Connecticut
}

\begin{abstract}
An experiment examined cross-modal interference and congruence in speeded classification: Subjects had to identify compound (visual-auditory) stimuli as either low or high in spatial position (visual judgment) or low or high in pitch (auditory judgment), in 16 conditions, each of which combined one of four possible pairs of tones, varying in frequency difference, with one of four possible pairs of dots, varying in positional difference. Both classification by position and classification by pitch revealed Garner interference (poorer performance than baseline, with orthogonal variation in the irrelevant dimension) and congruence effects (better performance with congruent than with incongruent stimulus combinations), but pitch classification showed more. Furthermore, the size of the pitch difference strongly affected classification by pitch and less strongly affected classification by position, but the size of the position difference affected neither. The findings are consistent with the view that Garner interference and congruence effects are closely related, perhaps arising from a common source, and suggest that the asymmetries could depend in part on the degree of dimensional overlap between stimuli and responses.
\end{abstract}

Research in recent decades has revealed complex, and not yet well understood, interactions in the perceptual processing of multimodal and multidimensional stimuli. Especially notable is research concerning the extent to which different components of complex stimuli are attended selectively - that is, perceived distinctively - and how various experimental parameters, such as the task and the nature of the stimulus, affect attentional selectivity (Garner, 1974, 1976; Lockhead, 1972, 1979; Shepard, 1964).

A stream of empirical works on the nature and variety of dimensional interactions emanated from Garner's (1974, 1976; Garner \& Felfoldy, 1970) theoretical and empirical formulations. Originally, Garner identified two categories of pairs of dimensions - namely, integral and separable-defining these categories in terms of patterns of performance in well-defined procedures of speeded classification. In speeded-classification experiments, subjects are asked to classify a complex stimulus according to its value on a single, relevant, experimenterdetermined dimension while ignoring the value on an irrelevant dimension. For example, the relevant dimension might be the pitch of a tone, and the irrelevant dimension might be its loudness (in the case of a unimodal auditory

This research was supported by Grant DC 0027 I from the National Institutes of Health to L.E.M. We thank Laura Armstrong and Patricia $O^{\prime}$ Neill for their help in the data collection. Robert Haussmann for computer assistance, and Greg Ashby and John Monahan for thoughtful comments on an earlier version of the paper. Correspondence concerning this article should be addressed to E. Ben-Artzi, Department of Psychology, Bar-llan University, Ramat Gan 52900, Israel (e-mail: F4140l@vm.biu.ac.il) stimulus) or the position of a dot (in the case of a bimodal, auditory-visual stimulus). Response time (RT) is commonly the primary measure of performance.

Typically, the two stimulus dimensions are variously combined so as to form three tasks:

1. In baseline classification, stimuli vary only in the dimension to be classified (relevant dimension) while the irrelevant dimension is held at a constant value. Classification performance in baseline tasks indicates the ease with which each dimension is identified separately, thereby making it possible to compare performance on the two dimensions.

2. In correlated classification, the two dimensions vary together, either positively or negatively. Superior performance (shorter RT) in tasks using correlated dimensions relative to baseline is presumably related to the fact that, on each trial, the value on the relevant dimension can be fully predicted by the value on the irrelevant dimension. Such superiority is termed a redundancy effect, and it indicates that information from a putatively irrelevant dimension can facilitate perceptual classification. Note, however, that the presence of redundancy gain is not crucial for making assertions about selectivity of attention (see Ashby \& Maddox, 1994; Mullennix \& Pisoni, 1990; Repp \& Lin, 1990).

3. In orthogonal classification, all possible values on the two dimensions are combined orthogonally, eliminating the possibility of reliably predicting the value on one dimension from that on the other. Orthogonal classification is also called a filtering task, after Posner's (1964) definition, for the subject is required to filter out the variation on the irrelevant dimension while attending to the relevant dimension. In speeded-classification par- 
adigms, the ability to attend selectively to one dimension is quantified by the difference between performance in orthogonal tasks and baseline tasks: The greater the RT in orthogonal tasks relative to baseline, a measure known as Garner interference (Pomerantz, 1983, 1986), the more difficult it is to attend selectively to the relevant dimension.

Since the early 1970 s, many researchers have investigated the perceptual relations between various pairs of dimensions. Their findings reveal two basic types of interdimensional perceptual relation: interacting and separable. With interacting pairs of dimensions, such as brightness and saturation, performance on orthogonal tasks is worse than that at baseline, but performance on correlated tasks is better. With separable dimensions such as color and shape, on the other hand, performance is equivalent on all three tasks. Nonetheless, recent studies suggest that dimensional interaction depends also on determinants of the task and the stimuli involved, such as instructions encouraging more integral or separable processing of the dimensions (Foard \& Kemler Nelson, 1984; Melara, Marks, \& Lesko, 1992; Smith \& Kemler Nelson, 1984) and the size of the difference between the values on the irrelevant dimension (Melara \& Mounts, 1994). Akin to the ways in which judgments of perceptual magnitudes depend on stimulus context (e.g., Marks, 1988, 1992), both Garner interference and congruence in loudness classification increase monotonically as the difference between the (irrelevant) values of pitch increase in size (Melara \& Mounts, 1994).

Melara and Mounts's (1994) findings suggest that the dimensional interactions evident in speeded classification depend systematically on the values on the irrelevant stimulus dimension. In the limiting case, of course, when the difference between the values on the irrelevant dimension is reduced to the point at which they become virtually indistinguishable, even without time constraint (i.e., reducing the difference to less than a JND), from the subject's perspective there would be no perceptual variation on the irrelevant dimension, and, consequently, the filtering task would essentially become a baseline task. So it is not surprising to find that increasing the difference between values on the irrelevant dimension acts, over some range of values, to increase the degree of Garner interference and congruence. On the other hand, we might expect that holding the values on the irrelevant dimension constant and increasing the difference between the values on the relevant dimension might reduce the amount of Garner interference; this prediction follows from the expectation that the greater the difference between stimuli being classified, the easier it is to attend selectively. This matter is explored in the present study, which asks how the choice of values on both the relevant and the irrelevant stimulus dimensions affects performance.

Melara and Mounts (1994) tested the auditory dimensions of loudness and pitch, a pair of dimensions that not only interact (i.e., show Garner interference) but also are, in Garner's terms, integral; that is, every auditory percept must have coexisting values of loudness and pitch (and, according to some accounts, integral dimensions interact in speeded classification because early processing is holistic: Garner, 1974; Lockhead, 1972, 1979; Shepard, 1964). Even if some pairs of interacting dimensions are initially processed holistically (a view that has been questioned, e.g., by Melara, Marks, $\&$ Potts, 1993), others almost certainly are not. Although Garner (1974) originally categorized pairs of dimensions as either integral (showing Garner interference) or separable (not showing interference), subsequent research revealed interacting pairs of dimensions that cannot easily be categorized as integral (Callaghan, Lasaga, \& Garner, 1986; Carrell, Smith, \& Pisoni, 1981; Marks, 1987; Melara, 1989; Melara \& Marks, 1990a; Melara \& O'Brien, 1987; Mullennix \& Pisoni, 1990; Pomerantz, 1983, 1986; for a review, see Pomerantz, Pristach, \& Carson, 1989) and that suggest, further, the existence of a broad category of interacting dimensions that may not necessarily be processed holistically.

Notable among nonintegral but interacting pairs are cross-modally corresponding dimensions, the topic of the present study. With bimodal stimuli in which the auditory component varies in pitch and the visual component varies in vertical position, pitch and position interact, Garner interference and congruence being hallmarks of these interactions. Yet stimuli compounded of tones and lights are presumably not processed initially as wholes. Pitch and position, as well as several other pairs of auditory and visual dimensions (e.g., pitch and brightness), themselves show communality in several domains besides speeded classification, such as synesthesia (see Marks, 1975, 1978), cross-modal matching and similarity (e.g., Marks, 1974, 1978, 1987, 1989; Marks, Hammeal, \& Bornstein, 1987; Melara \& O'Brien, 1987), and cross-modal metaphor (Marks, 1982a, 1982b; Marks et al., 1987). As already mentioned, a notable feature of cross-modal interactions in speeded classification is the presence of a Stroop-like congruence effect: Responses are faster to congruent pairs of stimuli (e.g., high auditory pitch/high visual position) than to incongruent pairs (e.g., high pitch/low position) (Marks, 1987; Melara \& Marks, 1990a, 1990b). The presence of synesthetic relations between pairs of dimensions, such as pitch and brightness, pitch and position, and pitch and shape, suggest that cross-modally corresponding dimensions are processed by a common perceptual or semantic mechanism.

The present study asks whether and how interactions between the cross-modally interacting dimensions of pitch and position depend on $\Delta_{\mathrm{pi}}$, the difference between the values of sound frequency, and on $\Delta_{\mathrm{po}}$, the difference between the vertical spatial positions. Studies to date on visual-auditory interactions in speeded classification have assigned a single pair of stimulus levels to each signal; for instance, a study of auditory pitch and visual position might test performance with a single pair of sound frequencies and a single pair of dots displayed in the vertical plane. Yet it seems likely that the ability to attend selectively to either dimension will depend on the 
choice of stimulus values on both dimensions. For example, a common view is that dimensional interaction is greatest when the values on the relevant and irrelevant dimensions produce equal baseline performance -implying that information on both dimensions is processed at about the same speed. By manipulating both $\Delta_{\text {po }}$ and $\Delta_{\text {pi }}$ systematically in this study, we produce stimulus conditions in which baseline performance is better in identification of position, better in identification of pitch, and the same in both (cf. Melara \& Mounts, 1994).

A possible outcome of special interest is interaction (e.g., Garner interference) when baseline performance is actually worse on the irrelevant dimension than on the relevant dimension. In such a case, the existence of interference produced by orthogonal variation in the irrelevant dimension would imply that even partial information accruing on that dimension can affect classification, an outcome particularly compatible with accrual models of RTs in information processing (e.g., Petrusic, 1992; Vickers, 1970). In this regard, results of Melara and O'Brien (1987) suggest strong asymmetry in pitch-position interactions: Melara and O'Brien found much greater Garner interference when subjects classified by pitch while position varied orthogonally than when subjects classified by position while pitch varied orthogonally; and congruence effects were greater in judgments of pitch than in judgments of position. Unfortunately, baseline performance in that study was substantially better when subjects judged position rather than pitch; thus, the asymmetry in the results might be the fortuitous outcome of the position differences' being more "potent" than the pitch differences, with information about position being processed more rapidly.

Alternatively, however, there may exist ineluctable asymmetries in the processing of visual and auditory information (see, e.g., Colavita \& Weisberg, 1979; Egeth $\&$ Sager, 1977). These asymmetries are typically explained by proposing that visual signals tend to be sampled first (Colavita, 1974) or receive relatively more attention than auditory signals (Colavita \& Weisberg, 1979; Egeth \& Sager, 1977; Posner, Nissen, \& Klein, 1976). To compare conditions in which baseline performance on the relevant and irrelevant dimension is both matched and mismatched may help clarify the processes underlying visual-auditory interactions.

\section{METHOD}

\section{Subjects}

Five men and seven women with no hearing problems were paid $\$ 6$ per hour to participate. The subjects were mostly students from Yale University.

\section{Stimuli and Apparatus}

The experiment was conducted with a PC $486 \mathrm{DX}$ computer operating at $33 \mathrm{MHz}$, which produced the visual stimuli and measured the response time in milliseconds. Visual stimuli were 0.4 $\mathrm{cm}$ dots positioned above or below the midline of the $20.5 \times$ $27.7 \mathrm{~cm}$ monitor; viewed at a distance of $50 \mathrm{~cm}$, each dot subtended a visual angle of $0.45^{\circ}$. Auditory signals were sinusoids produced by a signal-generating module (Coulbourn Instruments,
Lehigh Valley, PA), whose output, cont rolled by the computer, was gated with 25-msec rise and decay, amplified, attenuated, and then delivered to a Realistic Minimus speaker. Signal levels were calibrated ( $\mathrm{dB}$ on the $\mathrm{C}$ scale) with a General Radio 1565-B sound level meter. The experiment was controlled by a combined $\mathrm{QBa}-$ sic/Turbo Pascal program. RTs were measured with a dedicated Turbo Pascal unit (Haussmann, 1992)

Each trial comprised a combination of a low-pitched or highpitched tone and a low-positioned or high-positioned dot. Thus there were four possible stimuli in each experimental conditionlow pitch-low position, low pitch-high position, high pitch-low position, and high pitch-high position. Further, by defining 4 different pairs of values of low and high frequency and 4 different pairs of values of low and high spatial position, we produced 16 different experimental conditions. Pairs of frequencies were: 600 and $680 \mathrm{~Hz} ; 460$ and $820 \mathrm{~Hz} ; 320$ and $960 \mathrm{~Hz}$; and 180 and $1100 \mathrm{~Hz}$; thus $\Delta_{\mathrm{pi}}$ varied from 80 to $920 \mathrm{~Hz}$, with center frequency constant at $640 \mathrm{~Hz}$. The visual stimuli were dots positioned high and low. The pairs of dot positions, above and below midline, were as follows: $5 \mathrm{~cm}$ above and $5 \mathrm{~cm}$ below $\left(2.85^{\circ}\right) ; 7 \mathrm{~cm}$ and $7 \mathrm{~cm}\left(3.96^{\circ}\right)$; $9 \mathrm{~cm}$ and $9 \mathrm{~cm}\left(5.14^{\circ}\right)$; and $11 \mathrm{~cm}$ and $\| \mathrm{cm}\left(6.28^{\circ}\right)$. Thus, $\Delta_{\mathrm{po}}$ varied from 10 to $22 \mathrm{~cm}$.

\section{Tasks}

Five pitch-classification tasks and five position-classification tasks were constructed for each condition. Among each set of five tasks, two were single-dimension (baseline) tasks, one was a positively correlated dimensions task, one was a negatively correlated dimensions task, and one was an orthogonal-dimensions task. Each task consisted of 24 trials, and every set of five tasks was preceded by a practice run of 24 trials, identical to one of the two baseline tasks for the dimension to be classified. Practice runs were counterbalanced across subjects and conditions. In single-dimension tasks, subjects identified stimuli as low or high on one dimension while the value on the other dimension was held constant at one of the two possible values. For example, in one of the singledimension pitch-identification tasks, all tones were paired with the low-positioned dot, whereas in the other single-dimension pitch-identification task, all tones were paired with the highpositioned dot. In the two correlated-dimensions tasks, the value on the relevant dimension varied in either positive or negative correlation with the value on the irrelevant dimension. In the positively correlated position task, for instance, the high-positioned dot was always paired with the high-pitched tone, and the low-positioned dot was always paired with the low-pitched tone. Finally, in the orthogonal-dimensions tasks, both possible values on the irrelevant dimension were randomly associated with each value on the relevant dimension. Thus, in these tasks, both the high-pitched and the low-pitched tones were paired with low-positioned dots in half of the trials and with high-positioned dots in the other half of the trials. Order of trials within a task was randomized differently for each subject and for each condition. In total, subjects performed 3,840 trials $(24$ trials per task $\times 10$ tasks per condition $\times 16$ stimulus conditions), plus practice trials, over the course of five sessions

\section{Procedure}

The experiment was conducted in a darkened, sound-isolated room. The height of the screen was adjusted individually for each subject in order to align the subject's eyes with the screen's midline. Each session began with a loudness match, determined by using a modified method of limits: The subject heard four sequences of pairs of tones: a constant-level (70-dB) high-frequency tone and a variable-level low-frequency tone; in two sequences, the low tone increased in level in steps of $1.5 \mathrm{~dB}$, starting at $60 \mathrm{~dB}$, and in the other two, the low tone decreased in level in similar steps, starting at $83 \mathrm{~dB}$. After each trial, the subject pressed one of two keys to indicate whether the tones were equal or different in loudness. and each sequence ended when the subject indicated that the loud- 
Table 1

Mean Reaction Times (in Milliseconds) for Judgments of Pitch and Position for Different $\Delta_{\mathrm{pi}} \mathrm{s}$ and $\Delta_{\mathrm{po}} \mathrm{s}$

\begin{tabular}{|c|c|c|c|c|c|c|c|c|c|c|c|c|c|c|c|c|}
\hline \multirow[b]{3}{*}{ Tasks } & \multicolumn{16}{|c|}{ Frequencies } \\
\hline & \multicolumn{4}{|c|}{$\begin{array}{c}600-680 \mathrm{~Hz} \\
\text { Position Difference }\end{array}$} & \multicolumn{4}{|c|}{$\begin{array}{c}460-820 \mathrm{~Hz} \\
\text { Position Difference }\end{array}$} & \multicolumn{4}{|c|}{$\begin{array}{c}320-960 \mathrm{~Hz} \\
\text { Position Difference }\end{array}$} & \multicolumn{4}{|c|}{$\begin{array}{c}180-1100 \mathrm{~Hz} \\
\text { Position Difference }\end{array}$} \\
\hline & 10 & 14 & 18 & 22 & 10 & 14 & 18 & 22 & 10 & 14 & 18 & 22 & 10 & 14 & 18 & 22 \\
\hline \multicolumn{17}{|l|}{ Pitch Judgments } \\
\hline Baseline & 372 & 376 & 392 & 386 & 354 & 373 & 360 & 336 & 350 & 347 & 336 & 346 & 356 & 349 & 393 & 353 \\
\hline Positively correlated & 345 & 344 & 353 & 379 & 332 & 341 & 353 & 331 & 335 & 326 & 309 & 321 & 327 & 329 & 367 & 331 \\
\hline Negatively correlated & 381 & 397 & 403 & 413 & 362 & 374 & 347 & 339 & 352 & 346 & 336 & 356 & 375 & 365 & 384 & 350 \\
\hline Orthogonal & 382 & 391 & 410 & 412 & 370 & 375 & 379 & 357 & 377 & 363 & 374 & 364 & 381 & 371 & 429 & 368 \\
\hline \multicolumn{17}{|l|}{ Position Judgments } \\
\hline Baseline & 330 & 322 & 336 & 351 & 342 & 345 & 344 & 318 & 349 & 338 & 329 & 329 & 348 & 346 & 362 & 341 \\
\hline Positively correlated & 331 & 321 & 323 & 342 & 316 & 333 & 327 & 311 & 331 & 320 & 318 & 319 & 323 & 321 & 340 & 328 \\
\hline Negatively correlated & 334 & 338 & 326 & 345 & 335 & 336 & 330 & 309 & 347 & 321 & 330 & 327 & 344 & 342 & 355 & 336 \\
\hline Orthogonal & 335 & 336 & 334 & 350 & 349 & 366 & 340 & 333 & 372 & 334 & 335 & 337 & 357 & 361 & 384 & 345 \\
\hline
\end{tabular}

Note-Position difference is given in centimeters.

nesses were equal. The $\mathrm{dB}$ level of the low-pitched tone, averaged across the four sequences, was defined as a match and then used within the subsequent test condition. Thus this loudness-matching procedure preceded each of the 16 conditions.

After matching tones for loudness, subjects performed the two sets of five classification tasks. Each set was preceded by a singledimension practice run that varied randomly across subjects and conditions. All five tasks for each dimension were performed in sequence as a set. Order of sets within a condition was counterbalanced across conditions and across subjects, and order of tasks within each set was randomized differently for each condition and subject. Prior to each set, subjects read instructions on the screen informing them whether the dimension to be classified was pitch or position.

Each trial consisted of a combination of tone (low or high) and dot (low or high). The subject's task was to press the key labeled "low" or "high" for a low or high tone or dot, depending on the task. The subject initiated each trial by pressing the space bar. The stimuli appeared $1 \mathrm{sec}$ later and disappeared when the subject pressed either response key. For each subject, the same assignment of keys served for both dimensions and remained constant throughout the sessions. The keys assigned to low and high responses were counterbalanced across subjects. RTs and errors were automatically recorded. Only correct responses were further analyzed. Responses longer than $800 \mathrm{msec}$ were followed by a written message asking subjects to try to respond faster. Prior to each task, the subjects were informed of the dimension to be classified and were instructed to ignore the irrelevant dimension. However, the instructions emphasized that the subject should look at the monitor throughout the ex- periment and respond as quickly and accurately as possible. Following each task, subjects were informed of their RTs and errors. Each condition lasted approximately $15 \mathrm{~min}$, and subjects performed three conditions in the first four sessions and four conditions in the last session. Sessions were usually $1-3$ days apart.

\section{RESULTS}

RTs (in milliseconds) were averaged and percentages of errors were computed over trials and subjects, separately for each possible combination of stimuli (condition) within each task. Average RTs and error percentages appear in Tables 1 and 2, respectively. The overall error rate was $6.5 \%$, typical for speeded classification; in general, response speed and accuracy covaried positively, with longer RTs associated with higher rates of errors; because RTs provide a more sensitive measure of performance, they serve here as the focus of the analysis.

In general, as described in detail below, there were five main findings:

1. Overall - that is, pooled over all tasks and all values of the stimuli-classification by position was better than classification by pitch

2. Classification of both pitch and position showed Garner interference and congruence interactions.

Table 2

Percentage of Errors for Judgments of Pitch and Position for Different $\Delta_{\mathrm{pi}} \mathrm{s}$ and $\Delta_{\mathrm{po}} \mathrm{s}$

\begin{tabular}{|c|c|c|c|c|c|c|c|c|c|c|c|c|c|c|c|c|}
\hline \multirow[b]{3}{*}{ Tasks } & \multicolumn{16}{|c|}{ Frequencies } \\
\hline & \multicolumn{4}{|c|}{$\begin{array}{c}600-680 \mathrm{~Hz} \\
\text { Position Difference }\end{array}$} & \multicolumn{4}{|c|}{$\begin{array}{c}460-820 \mathrm{~Hz} \\
\text { Position Difference }\end{array}$} & \multicolumn{4}{|c|}{$\begin{array}{c}320-960 \mathrm{~Hz} \\
\text { Position Difference }\end{array}$} & \multicolumn{4}{|c|}{$\begin{array}{c}180-1100 \mathrm{~Hz} \\
\text { Position Difference }\end{array}$} \\
\hline & 10 & 14 & 18 & 22 & 10 & 14 & 18 & 22 & 10 & 14 & 18 & 22 & 10 & 14 & 18 & 22 \\
\hline \multicolumn{17}{|l|}{ Pitch Judgments } \\
\hline Baseline & 8.3 & 12.7 & 10.1 & 11.1 & 6.8 & 5.4 & 6.1 & 6.4 & 5.2 & 6.1 & 6.2 & 8.2 & 5.9 & 6.8 & 6.6 & 5.2 \\
\hline Positively correlated & 5.2 & 6.9 & 4.5 & 2.1 & 4.2 & 1.4 & 4.5 & 4.2 & 3.8 & 1.7 & 4.2 & 2.4 & 3.8 & 1.4 & 2.4 & 3.1 \\
\hline Negatively correlated & 11.8 & 14.2 & 13.9 & 13.2 & 5.2 & 9.0 & 6.2 & 6.9 & 5.9 & 4.9 & 4.9 & 6.6 & 7.6 & 6.6 & 4.9 & 3.8 \\
\hline Orthogonal & 12.8 & 12.8 & 12.1 & 13.9 & 7.6 & 10.1 & 13.9 & 10.4 & 9.0 & 12.1 & 9.0 & 9.4 & 10.8 & 10.1 & 10.4 & 8.3 \\
\hline \multicolumn{17}{|l|}{ Position Judgments } \\
\hline Baseline & 8.5 & 6.8 & 5.6 & 8.0 & 8.0 & 6.2 & 5.6 & 6.2 & 6.4 & 5.2 & 5.7 & 6.4 & 6.9 & 6.9 & 4.7 & 5.0 \\
\hline Positively correlated & 8.3 & 5.2 & 4.2 & 3.1 & 4.2 & 2.4 & 3.1 & 4.2 & 4.2 & 4.2 & 3.5 & 2.1 & 3.1 & 2.4 & 1.7 & 2.1 \\
\hline Negatively correlated & 7.6 & 6.6 & 4.9 & 10.4 & 2.8 & 5.2 & 4.2 & 3.8 & 5.2 & 2.1 & 4.2 & 3.8 & 9.4 & 6.6 & 6.6 & 3.8 \\
\hline Orthogonal & 5.2 & 6.2 & 6.6 & 9.4 & 7.3 & 5.2 & 5.6 & 7.3 & 5.9 & 7.3 & 6.9 & 6.3 & 10.8 & 5.2 & 2.8 & 6.6 \\
\hline
\end{tabular}

Note-Position difference is given in centimeters. 
3. Interference and congruence alike were greater when subjects classified by pitch than by position.

4 . Whereas the difference in pitch $\left(\Delta_{\mathrm{pi}}\right)$ modified classification by both pitch and position, the difference in position $\left(\Delta_{\mathrm{po}}\right)$ had no effect.

5. Congruence effects were consistently evident when subjects classified by pitch but much less so when they classified by position and were greatest in orthogonal tasks.

Two four-way multivariate analyses of variance (MANOVAs) for repeated measures were applied to RTs and to error rates, with dimension (pitch, position), pitch difference $(80,360,640,920 \mathrm{~Hz})$, position difference $(10,14,18,22 \mathrm{~cm})$, and task (baseline, positive, negative, orthogonal) as within-subjects variables.

\section{Overall Performance}

Consistent with previous reports, classification by position was on the whole better than classification by pitch, as manifested in both smaller RTs [ 337 vs. 362 msec; $\left.F(1,11)=12.14, M S_{\mathrm{e}}=20,543.03, p<.01\right]$ and lower error rates $\left[5.7 \%\right.$ vs. $7.3 \% ; F(1,11)=7.33, M S_{\mathrm{e}}=$ $182.97, p<.05]$.

\section{Selective Attention: Effect of Task}

Overall performance varied across the four tasks, as manifested in both speed $\left[F(3,33)=41.55, M S_{\mathrm{e}}=\right.$ $1,663.68, p<.001]$ and accuracy $[F(3,33)=23.22$, $\left.M S_{\mathrm{e}}=74.33, p<.001\right]$. Pairwise $t$ tests (two-tailed, here and in subsequent analyses) revealed that performance in negatively correlated tasks did not differ from performance at baseline, in either RT ( $351 \mathrm{vs.} 350 \mathrm{msec}$ ) or errors $(6.7 \%$ vs. $6.9 \%)$, but that performance in positively correlated tasks was faster than that in baseline tasks [332 vs. $350 \mathrm{msec} ; t(1 \mathrm{l})=7.45, p<.001]$ and showed a lower error rate $[3.6 \%$ vs. $6.9 \% ; t(11)=5.29, p<.001]$. On the other hand, performance in orthogonal tasks was slower than that at baseline [364 vs. $350 \mathrm{msec} ; t(11)=$ $5.85, p<.00 \mathrm{I}]$ and less accurate $[8.7 \%$ vs. $6.9 \%$ of errors; $t(11)=3.64, p<.01]$. Thus the results show the typical pattern of dimensional interaction: failure of selective attention, indicated by the presence of Garner interference with orthogonal variation in the irrelevant dimension, and some improvement in performance with positively correlated dimensions.

Quantitatively, however, variation in the irrelevant dimension did not affect classification by pitch and by position equally. Performance at pitch classification differed more across tasks than did performance at position classification, as indicated by the significant interaction of dimension (pitch, position) $\times$ task (baseline, positive, negative, orthogonal), which emerged for both RTs $\left[F(3,33)=4.93, M S_{\mathrm{e}}=1,782.15, p<.01\right]$ and errors $\left[F(3,33)=6.90, M S_{\mathrm{e}}=50.90, p<.01\right]$. Pairwise $t$ tests, computed on RTs for different tasks, revealed different patterns of results with judgments of pitch and position: With pitch judgments, positively correlated tasks were $22 \mathrm{msec}$ faster than baseline tasks $[t(11)=5.17, p<$ $.001]$, orthogonal tasks were $20 \mathrm{msec}$ slower than base- line tasks $[t(11)=6.97, p<.001]$, and negatively correlated tasks did not differ reliably from baseline $(6 \mathrm{msec}$; n.s.). With position judgments, positively correlated tasks were $14 \mathrm{msec}$ faster than baseline tasks $[t(11)=$ $7.1, p<.001]$, orthogonal tasks were $9 \mathrm{msec}$ slower than baseline tasks $[t(11)=2.22, p<.05]$, and negatively correlated tasks were slightly faster $(5 \mathrm{msec})$ than baseline tasks $[t(11)=2.21, p<.05]{ }^{1}$

\section{Effect of Stimulus Difference}

Figure 1 presents overall RTs for judgments of pitch and position as a function of $\Delta_{\mathrm{pi}}$ (pooled over all values of $\Delta_{\mathrm{po}}$ ), and Figure 2 presents RTs for pitch and position judgments as a function of $\Delta_{\mathrm{po}}$ (pooled over all values of $\Delta_{\mathrm{pi}}$ ). The difference in mean RTs is clear: Whereas $\Delta_{\mathrm{po}}$ had virtually no effect on either pitch or position judgments, $\Delta_{\text {pi }}$ had a relatively large effect on pitch judgments and a smaller effect on position judgments-an outcome that is supported statistically by the significant dimension $\times$ pitch difference interaction in RTs $\left[F(3,33)=7.10, M S_{\mathrm{e}}=3,482.73, p<.001\right]$. Pairwise $t$ tests revealed that in pitch judgments, RT was $37 \mathrm{msec}$ greater when $\Delta_{\mathrm{pi}}=80 \mathrm{~Hz}$ than when $\Delta_{\mathrm{pi}}=640 \mathrm{~Hz}$ $[t(11)=2.31, p<.05]$, which in turn was marginally smaller $(18 \mathrm{msec})$ than when $\Delta_{\mathrm{pi}}=920 \mathrm{~Hz}[t(11)=$ $2.12, p=.057]$. In position judgments, RT was $12 \mathrm{msec}$ greater when $\Delta_{\mathrm{pi}}=920 \mathrm{~Hz}$ than when $\Delta_{\mathrm{pi}}=640 \mathrm{~Hz}$ $[t(11)=2.45, p<.05]$, with all other differences nonsignificant. Thus the size of the pitch difference strongly affected pitch and less strongly affected position judgments, while the size of the position difference affected neither. Measures of error rates showed very similar patterns of results, as shown in Figures 3 and 4. Again, variation in $\Delta_{\text {po }}$ did not affect either kind of judgmeni, as indicated by the nonsignificant dimension $\times$ position difference interaction in errors, whereas variation in $\Delta_{\mathrm{pi}}$ had a stronger effect on classifications by pitch than on classifications by position, as reflected by the significant

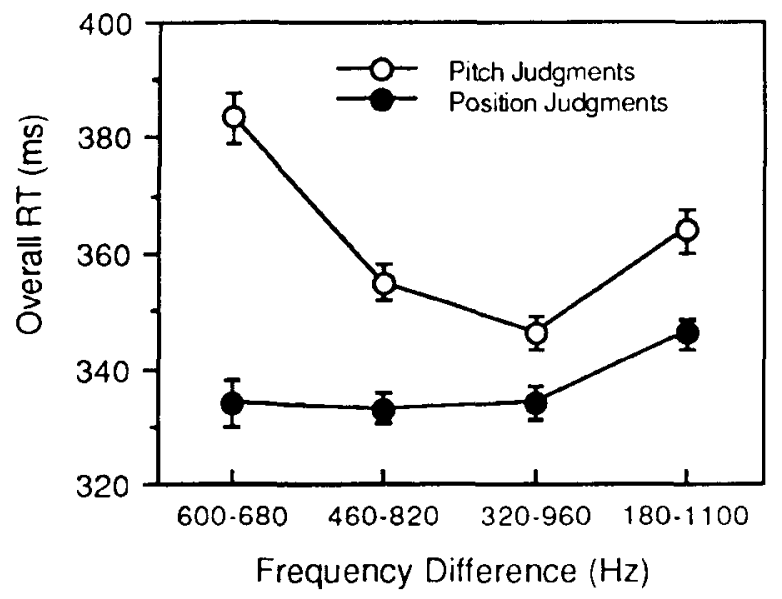

Figure 1. Mean overall response times (RTs) by frequency (pitch) difference for judgments of pitch and position. Error bars represent only within-subjects' standard errors, after variation between subjects was removed. 


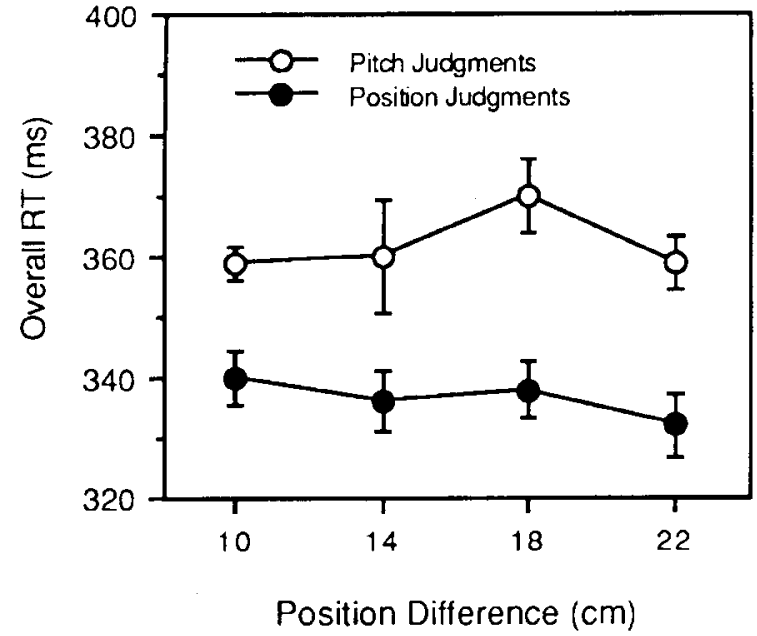

Figure 2. Mean overall response times (RTs) by position difference for judgments of pitch and position. Error bars represent only within-subjects' standard errors, after variation between subjects was removed.

dimension $\times$ pitch difference interaction in errors $[F(3,33)$ $\left.=5.09, M S_{\mathrm{e}}=30.53, p<.01\right]$.

\section{Effect of Stimulus Difference at Baseline}

The asymmetrical effects of $\Delta_{\mathrm{pi}}$ and $\Delta_{\mathrm{po}}$ on speed in classifying by pitch and by position are even more clear when restricted to the RTs measured at baseline, as shown in Figures 5 and 6. A three-way MANOVA for repeated measures applied to baseline RTs, with dimension (pitch, position), pitch difference $(80,360,640$, $920 \mathrm{~Hz})$, and position difference $(10,14,18,22 \mathrm{~cm})$ as within-subjects variables, revealed a significant dimension $\times$ pitch difference interaction $[F(3,33)=10.52$, $\left.M S_{\mathrm{e}}=667.02, p<.001\right]$. Two MANOVAs for repeated measures applied to baseline RTs, with the variable of pitch difference, conducted separately for pitch and position judgments, indicated that $\Delta_{\mathrm{pi}}$ affected the former $\left[F(3,33)=3.70, M S_{\mathrm{e}}=3,035.5, p<.05\right]$, but not the latter $(F=.99)$. Pairwise $t$ tests revealed pitch judgments to be significantly slower with small pitch differences $\left(\Delta_{\mathrm{pi}}=80 \mathrm{~Hz}\right)$ than larger ones $\left[\Delta_{\mathrm{pi}}=640 \mathrm{~Hz} ; 381\right.$ vs. $345 \mathrm{msec} ; t(11)=2.69, p<.05$ ], presumably reflecting a "floor effect" at the large values of $\Delta_{\mathrm{pi}}$.

Next, compare position judgments and pitch judgments at baseline, separately for each of the 16 conditions. Judgments of pitch were slower than those of position when $\Delta_{\mathrm{pi}}$ was smallest $\left(\Delta_{\mathrm{pi}}=80 \mathrm{~Hz}\right)$, regardless of the value of $\Delta_{\text {po }}$. No reliable difference in RT between pitch and position classification in baseline tasks emerged at any other level of $\Delta_{\mathrm{pi}}$ or $\Delta_{\mathrm{po}}$. Statistically, a MANOVA applied to baseline RTs, with the variables of condition (16) and dimension (pitch, position), revealed an interaction between them $\left[F(15,165)=2.40, M S_{\mathrm{e}}=\right.$ $756.68, p<.01]$, indicating that baseline judgments of pitch and position depended on the specific combination of pitch and position difference. Pairwise $t$ tests at each of the 16 conditions revealed a significant advantage of position over pitch judgments when $\Delta_{\text {pi }}$ was smallest, $80 \mathrm{~Hz}$ (all values of $p<.05$ for these four conditions), again reflecting the floor effect with large $\Delta_{\mathrm{p} \text {. }}$. Therefore, the degree of asymmetry between processing auditory and visual signals depends to a much greater extent on the values of the auditory stimuli than on the values of the visual stimuli-at least with respect to processing the dimensions of pitch and position.

\section{Effect of Stimulus Difference on Selective Attention}

Particularly informative is comparison of Garner interference in conditions in which baseline RTs for pitch and position judgments matched and in those in which RTs did not match. When $\Delta_{\mathrm{pi}}$ equaled or exceeded

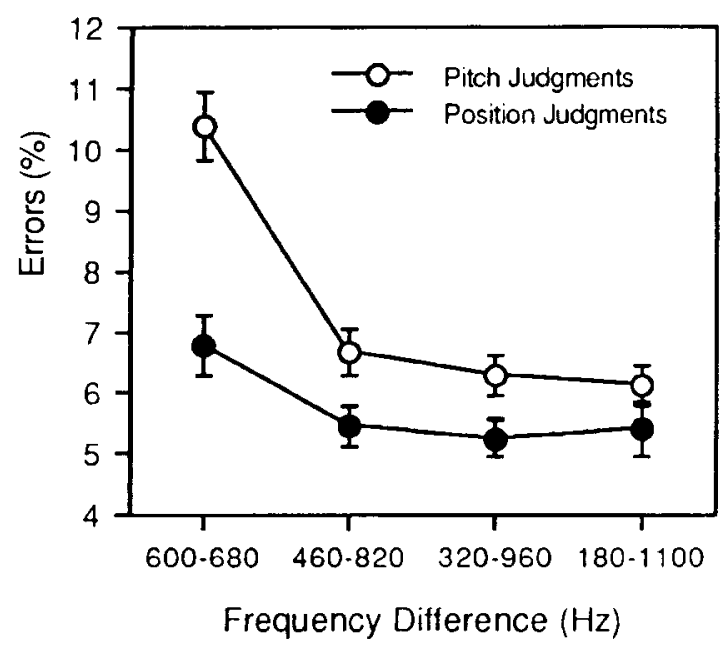

Figure 3. Mean percentage of errors by frequency (pitch) difference for judgments of pitch and position. Error bars represent only within-subjects' standard errors, after variation between subjects was removed.

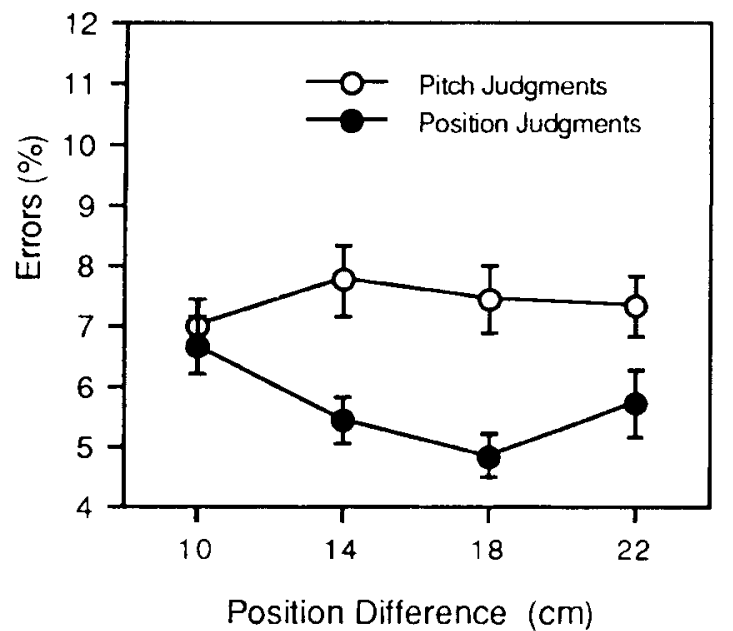

Figure 4. Mean percentage of errors by position difference for judgments of pitch and position. Error bars represent only withinsubjects' standard errors, after variation between subjects was removed. 


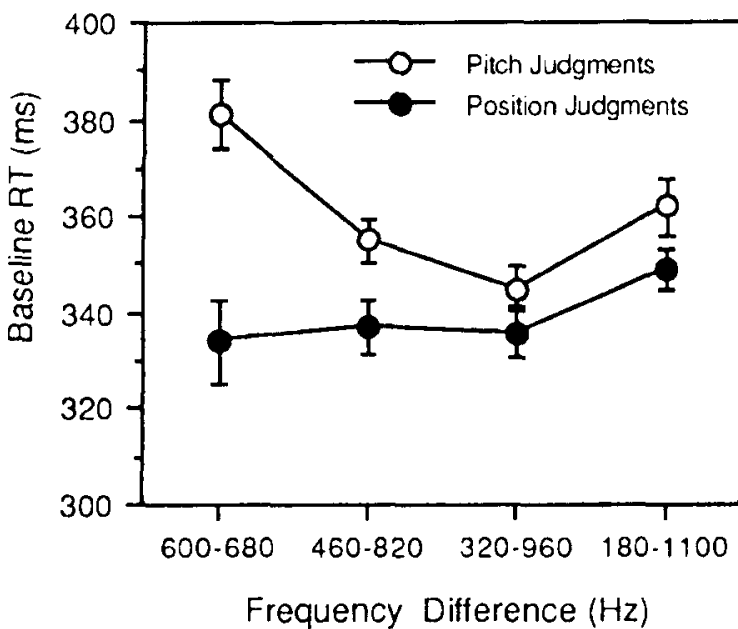

Figure 5. Mean baseline response times (RTs) by frequency (pitch) difference for judgments of pitch and position. Error bars represent only within-subjects' standard errors, after variation between subjects was removed.

$360 \mathrm{~Hz}$ - that is, in 12 of the 16 conditions - baseline RTs obtained with judgments of pitch and position were roughly equal; but when $\Delta_{\mathrm{pi}}$ was small $(80 \mathrm{~Hz})$, below the "floor"- that is, in the remaining four conditions baseline judgments of position were considerably faster.

Table 3 gives the differences between orthogonal and baseline RTs (i.e., Garner interference) for pitch and position judgments. In the dozen conditions in which baseline RTs for pitch and position judgments did not differ reliably (in which $\Delta_{\mathrm{pi}} \geq 360 \mathrm{~Hz}$ ), interference was clearly more substantial in judgments of pitch than in judgments of position. Pairwise $t$ tests indicated that pitch judgments showed reliable amounts of Garner interference in

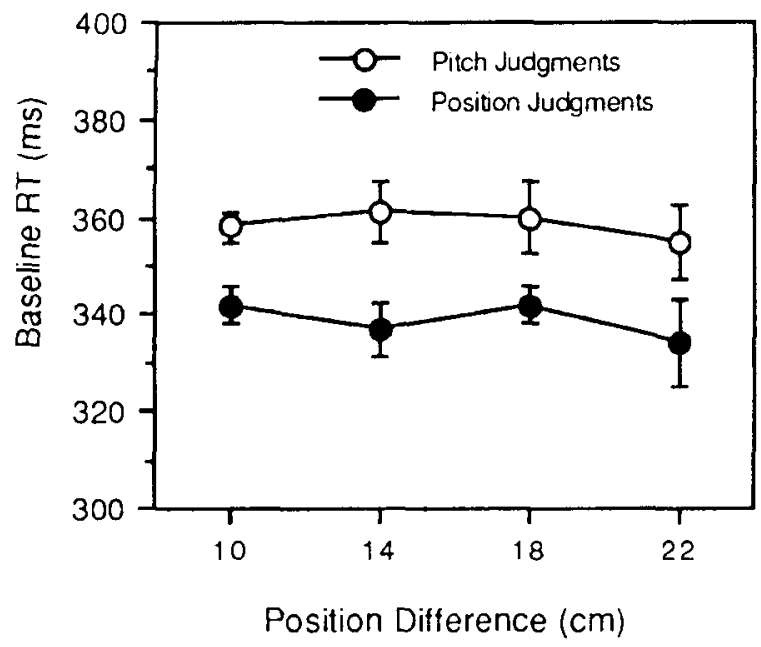

Figure 6. Mean baseline response times (RTs) by position difference for judgments of pitch and position. Error bars represent only within-subjects' standard errors, after variation between subjects was removed. seven conditions, whereas position judgments showed reliable amounts in only two. We inspected the baseline RTs in each of the seven conditions in which Garner interference emerged only in judgments of pitch but not in judgments of position. In four of these conditions, baseline RTs for judgments of pitch and position were not only statistically indistinguishable but numerically almost identical. For $\Delta_{\mathrm{pi}}=920 \mathrm{~Hz}$ and $\Delta_{\mathrm{po}}=14 \mathrm{~cm}$, the difference in baseline RTs for judgments of pitch and position was $3 \mathrm{msec}$; for $\Delta_{\mathrm{pi}}=920 \mathrm{~Hz}$ and $\Delta_{\mathrm{po}}=10 \mathrm{~cm}$ the difference was $8 \mathrm{msec}$; for $\Delta_{\mathrm{pi}}=640 \mathrm{~Hz}$ and $\Delta_{\mathrm{po}}=$ $18 \mathrm{~cm}$, the difference was $7 \mathrm{msec}$, and for $\Delta_{\mathrm{pi}}=640 \mathrm{~Hz}$ and $\Delta_{\mathrm{po}}=10 \mathrm{~cm}$, the difference was only $1 \mathrm{msec}$. In the four conditions in which pitch judgments gave longer baseline RTs than did position judgments, pitch judgments did not show statistically significant Garner interference, although some interference was evident. However, in one of these conditions $-\Delta_{\mathrm{pi}}=80 \mathrm{~Hz}$ and $\Delta_{\mathrm{po}}=$ $14 \mathrm{~cm}$ - judgments of position do show a reliable Garner interference, amounting to $15 \mathrm{msec}(p<.05)$. In other words, although the irrelevant dimension, pitch, was classified more slowly at baseline than was the relevant dimension, position, variations in pitch nevertheless interfered with the classification by position. Moreover, except for 1 of the 16 conditions (in which $\Delta_{\mathrm{pi}}=360 \mathrm{~Hz}$ and $\Delta_{\mathrm{po}}=18 \mathrm{~cm}$ ), all conditions yielded asymmetric auditory-visual interactions, there typically being more visual interference with auditory classification than vice versa.

\section{Congruence Effects}

To analyze effects of congruence, the four stimuli were grouped in two categories: congruent combinations (high pitch and high position; low pitch and low position) and incongruent combinations (high pitch and low position; low pitch and high position). Then congruence scores were calculated for each task by subtracting RT for congruent stimuli from RT for incongruent stimuli. These scores are listed in Table 4 for each value of $\Delta_{\mathrm{pi}}$ and $\Delta_{\mathrm{po}}$.

A four-way MANOVA was applied to congruence scores for dimension, task (baseline, correlated, orthogonal), pitch difference, and position difference, and this revealed a significant main effect of dimension $[F(1,11)=$ $15.21, M S_{\mathrm{e}}=10,123.02, p<.01$ ], indicating that congruence scores were higher for pitch judgments $(30 \mathrm{msec})$ than for position judgments $(6 \mathrm{msec})$, and a significant main effect of task $\left[F(2,22)=8.02, M S_{\mathrm{e}}=7,603.52\right.$, $p<.01]$, indicating that congruence scores were greater in the correlated tasks $(19 \mathrm{msec})$ and orthogonal tasks $(30 \mathrm{msec})$ than at baseline $(5 \mathrm{msec})[t(11)=4.37, p<$ .01 , and $t(11)=3.37, p<.01$, respectively]. However, these variations across tasks revealed themselves only in pitch judgments and not in position judgments, as indicated by the significant dimension $\times$ task interaction $\left[F(2,22)=21.20, M S_{\mathrm{e}}=3,217.28, p<.001\right]$, and depended on the pitch difference, as indicated by the marginally significant dimension $\times$ pitch difference $\times$ task 
Table 3

Garner Interference for Judgments of Pitch and Position for Different $\Delta_{\mathrm{pi}} \mathrm{s}$ and $\Delta_{\mathrm{po}} \mathrm{s}$

\begin{tabular}{|c|c|c|c|c|c|c|c|c|c|c|c|c|c|c|c|c|}
\hline \multirow[b]{3}{*}{ Judgments } & \multicolumn{16}{|c|}{ Frequencies } \\
\hline & \multicolumn{4}{|c|}{$\begin{array}{c}600-680 \mathrm{~Hz} \\
\text { Position Difference }\end{array}$} & \multicolumn{4}{|c|}{$\begin{array}{c}460-820 \mathrm{~Hz} \\
\text { Position Difference }\end{array}$} & \multicolumn{4}{|c|}{$\begin{array}{c}320-960 \mathrm{~Hz} \\
\text { Position Difference }\end{array}$} & \multicolumn{4}{|c|}{$\begin{array}{c}180-1100 \mathrm{~Hz} \\
\text { Position Difference }\end{array}$} \\
\hline & 10 & 14 & 18 & 22 & 10 & 14 & 18 & 22 & 10 & 14 & 18 & 22 & 10 & 14 & 18 & 22 \\
\hline Pitch & 10 & 15 & 18 & $26 \neq$ & $16^{*}$ & 2 & 19 & $22^{*}$ & $27 \dagger$ & 15 & $38 \div$ & 18 & $25^{*}$ & $21^{*}$ & $37^{*}$ & 15 \\
\hline Position & 6 & $15^{*}$ & -1 & -1 & 6 & $21 *$ & -4 & $15^{*}$ & 22 & -4 & 6 & 8 & 10 & 14 & 22 & 5 \\
\hline
\end{tabular}

Note-Position difference is given in centimeters. ${ }^{*} p<.05 . \quad \dagger p<.01 . \quad \ddagger p=.07$.

interaction $\left[F(6,66)=2.20, M S_{\mathrm{e}}=2,469.47, p=.05\right]$. Two-way MANOVAs on congruence scores, using the variables of task and pitch difference, conducted separately on pitch judgments and position judgments, revealed no significant effects of pitch difference or task in judgments of position. In judgments of pitch, however, effects of both pitch difference and task were significant $\left[F(3,33)=13.18, M S_{\mathrm{e}}=1,223.69, p<.01\right.$, and $F(2,22)=$ $10.40, M S_{\mathrm{e}}=612.87, p<.01$, respectively], as was the interaction between pitch difference and task $[F(6,66)=$ $\left.2.34, M S_{\mathrm{e}}=890.00, p<.05\right]$. Pairwise $t$ tests indicated that for congruence scores, judgments of pitch were higher in correlated tasks $(29 \mathrm{msec})$ and in the orthogonal task $(56 \mathrm{msec})$ than at baseline $(4 \mathrm{msec})[t(11)=$ $4.39, p<.001$, and $t(11)=5.07, p<.001$, respectively]. Moreover, as shown in Figures $7 \mathrm{~A}$ and $7 \mathrm{~B}$, the size of the pitch difference affected congruence scores only in correlated tasks, with greater congruence scores for $\Delta_{\mathrm{pi}}=80 \mathrm{~Hz}(43.7)$ than for $\Delta_{\mathrm{pi}}=360 \mathrm{~Hz}$ (16.1) [t(11) = $2.44, p<.05]$.

\section{DISCUSSION}

The present findings suggest marked asymmetries in auditory-visual interactions between the dimensions of pitch and vertical position, as revealed in both Garner interference and congruence effects. To reiterate, there were five main results.

First, performance at orthogonal tasks was poorer than performance at baseline, and performance at positively correlated tasks was better than performance at baseline; but performance at negatively correlated tasks did not differ from that at baseline. This outcome held for classifications of both position and pitch and was manifested in both RTs and error rates.

Second, Garner interference (increase in RT and error rates in orthogonal tasks relative to baseline) was greater with classification of pitch than with classification of position, even when baseline levels of RT were equivalent. Thus, interactions themselves appear to be intrinsically asymmetric with regard to modality, pitch judgments being more susceptible to interference than position judgments.

Third, in baseline tasks, visual stimuli were classified more quickly than auditory stimuli. Note, however, that this was not universally true, for some pairs of auditory stimuli were classified as quickly as the visual stimuli (in general, baseline time for pitch classification decreased as frequency difference increased, but baseline time for position classification was independent of the stimulus difference); thus the particular results clearly can depend on the choice of stimulus values. Nevertheless, the results suggest that, where stimulus differences are large, and RT is asymptotically small, classification of visual position is probably faster than classification of auditory pitch.

Fourth, Garner interference was not only smaller in classification of position than pitch, but performance in classifying position was virtually independent of the levels of the visual and auditory stimuli. By way of contrast, performance in classifying pitch was poorer (overall RT and error rate were greater) and showed larger congruence effects when the pitch differences were small than when they were large. This outcome is consistent with

Table 4

Mean Congruence Scores (Incongruent Minus Congruent, in Milliseconds) for Judgments of Pitch and Position for Different $\Delta_{\mathrm{pi}} \mathrm{s}$ and $\Delta_{\mathrm{po}} \mathrm{s}$

\begin{tabular}{|c|c|c|c|c|c|c|c|c|c|c|c|c|c|c|c|c|}
\hline \multirow[b]{3}{*}{ Tasks } & \multicolumn{16}{|c|}{ Frequencies } \\
\hline & \multicolumn{4}{|c|}{$\begin{array}{c}600-680 \mathrm{~Hz} \\
\text { Position Difference }\end{array}$} & \multicolumn{4}{|c|}{$\begin{array}{c}460-820 \mathrm{~Hz} \\
\text { Position Difference }\end{array}$} & \multicolumn{4}{|c|}{$\begin{array}{c}320-960 \mathrm{~Hz} \\
\text { Position Difference }\end{array}$} & \multicolumn{4}{|c|}{$\begin{array}{c}180-1100 \mathrm{~Hz} \\
\text { Position Difference }\end{array}$} \\
\hline & 10 & 14 & 18 & 22 & 10 & 14 & 18 & 22 & 10 & 14 & 18 & 22 & 10 & 14 & 18 & 22 \\
\hline \multicolumn{17}{|c|}{ Pitch Judgments } \\
\hline Baseline & -9 & -6 & 0 & 2 & 15 & -9 & 8 & 9 & -2 & 11 & 1 & 3 & 18 & -1 & 5 & 22 \\
\hline Correlated & 37 & 54 & 51 & 34 & 29 & 33 & -6 & 8 & 17 & 20 & 27 & 35 & 48 & 36 & 18 & 19 \\
\hline Orthogonal & 51 & 69 & 55 & 69 & 45 & 54 & 49 & 56 & 77 & 76 & 40 & -14 & 78 & 60 & 82 & 48 \\
\hline \multicolumn{17}{|c|}{ Position Judgments } \\
\hline Baseline & 10 & 6 & 7 & 12 & 4 & -3 & 10 & 9 & 5 & -3 & 9 & 2 & 8 & 9 & 0 & 10 \\
\hline Correlated & 3 & 16 & 4 & 3 & 19 & 3 & 3 & -1 & 16 & 2 & 12 & 8 & 21 & 20 & 15 & 8 \\
\hline Orthogonal & -23 & -32 & -14 & 21 & 36 & 39 & -15 & 28 & 14 & 23 & -1 & 2 & 16 & 4 & -31 & 4 \\
\hline
\end{tabular}

Note-Position difference is given in centimeters. 

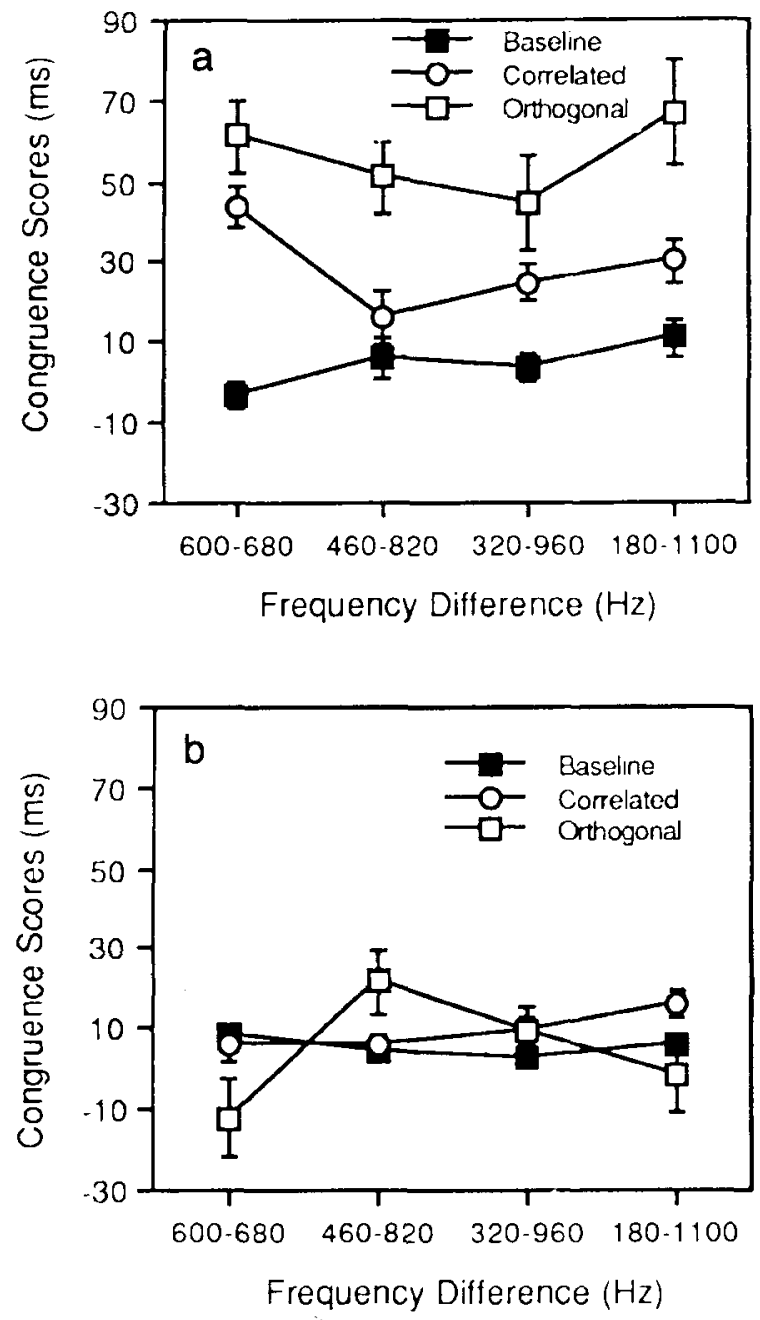

Figure 7. (a) Mean congruence scores for baseline, correlated, and orthogonal tasks by frequency (pitch) difference for judgments of pitch. Error bars represent only within-subjects' standard errors, after variation between subjects was removed. (b) Mean congruence scores for baseline, correlated, and orthogonal tasks by frequency (pitch) difference for judgments of position. Error bars represent only within-subjects' standard errors, after variation between subjects was removed.

the notion that the interactions in pitch judgments, but not position judgments, depend directly on the magnitude of the subjective differences on the relevant and irrelevant dimensions.

Fifth, strong congruence effects were evident when subjects classified by pitch, much less so when they classified by position, were greatest in orthogonal tasks, and depended only on the pitch difference and not on the position difference. It is possible, for instance, that pitch shares more with position than position shares with pitch, that pitch has some degree of "positionality," whereas spatial position lacks "pitchness," or that the overlap between the stimuli and responses- the characteristics of stimulus-response compatibility--in the present task depend on whether the relevant dimension is pitch or position, a conjecture to which we return later.
Taken as a whole, these findings conform to those of Melara and O'Brien (1987), and they suggest some kind of "priority" in the processing of visual over auditory stimuli. That is, the greater vulnerability of auditory classification to interference by orthogonal variation in an irrelevant visual stimulus, evident in the results of Melara and O'Brien, was probably not the fortuitous outcome of a mismatch in baseline levels of performance. Supporting the hypothesis of visual priority are findings obtained in cued RT tasks, in which visual and auditory stimuli, matched for subjective magnitude, have been presented together, showing that subjects respond predominantly to the visual stimulus, being unaware in some cases that the tone has even been presented (Colavita, 1974; Colavita, Tomko, \& Weisberg, 1976; Colavita \& Weisberg, 1979). This visual dominance was reduced but not abolished when the subjects were instructed to respond to the tones on conflicting trials, or when the tone was made twice as intense as the light (Colavita, 1974; Colavita et al., 1976).

In attempts to decide whether the locus of the effect was sensory or decisional-attentional, Egeth and Sager (1977) found that the visual dominance was independent of stimulus intensity but was affected by instructions and by the probability of light and tone trials, leading these investigators to conclude that visual dominance presumably involves high-level processes. Posner et al. (1976) have suggested that visual dominance derives from a tendency to compensate for the visual system's small intrinsic attentional-generating ability. In this view, because visual stimuli have weaker capacity to elicit attention than have auditory stimuli, we learn to direct attention to visual stimuli. Additional support for the attentional hypothesis of visual dominance is provided by Colavita and Weisberg (1979), who found dominance of vision over audition in cued RTs to the offset of the stimuli, a finding that can be explained better in terms of attentional rather than sensory differences.

Our inference that the visual modality is dominant over the auditory is based on the larger interference in pitch judgments than in position judgments when levels of pitch and position are equally discriminable. Given that pitch discriminability and position discriminability were virtually identical in four conditions, we tentatively conclude that these findings reflect a dominance of vision over audition. However, we must qualify this conclusion, because, in general, baseline RTs for position hover around a "floor" that is lower than the corresponding "floor" in baseline RTs for pitch. Therefore, it would be useful to examine visual-auditory interference with differences in position that are smaller than $10 \mathrm{~cm}$, and hence greater baseline RTs.

\section{Role of Stimulus-Response Compatibility}

Perhaps the asymmetries between processing of the visual and auditory signals are related to the degree of overlap between the percepts and the overt responses required in these tasks (cf. Kornblum, Hasbroucq, \& Osman, 1990). In particular, we suggest that there may 
be an intrinsic stimulus-response similarity, or perhaps a commonality, when subjects classify by spatial position, a similarity that resides jointly in the spatial character of the response processes and the perception of vertical spatial positions; such a similarity is lacking, or considerably weaker, when subjects classify by pitch. In the present experiment, and in other related ones, the response itself is based in a spatial relation - the subjects learn that one relevant stimulus is defined by the right key and the other by the left key, presumably without processing the position semantically in terms of "high" and "low." Because vertical position is, ipso facto, also spatial, we suggest that stimulus-response encoding may be particularly efficient under these circumstances, and, consequently, that encoding may be relatively immune to interference by irrelevant variations in other stimulus dimensions, such as pitch, whose spatiality is only tangential or weak (but see Marks, 1994).

This is to say that spatially based (whether left-right or other) responses to signals differing in position very likely are made in the absence of (or perhaps prior to) any conscious recognition of their position being high or low. By contrast, the spatial characteristic of auditory signals is presumably more modest, though perhaps not absent (cf. Roffler \& Butler, 1968). As a consequence, it may require greater cognitive mediation to link values of pitch to spatially defined responses. Given this line of reasoning, we tentatively suggest that the slow responses to pitch relative to responses to position, found in our study and others (e.g., Melara \& O'Brien, 1987), may result not only from intrinsic differences in the perceptual processing of these dimensions but also, to some extent at least, from differences in the degree of processing required in order to link pitch and position to spatially lateralized responses. Recall further that in only 2 out of 16 conditions did orthogonal variation in pitch affect classification by visual position, a finding that is also consistent with our view that processing of visual stimuli may not be only intrinsically faster than processing of auditory stimuli, but further that the spatial nature of the response permits a preferentially spatial, nonsemantic processing of the visual stimuli.

One implication is clear: One should consider other modes of response before generalizing from experiments of this type about the underlying perceptual processing. For instance, one might compare results obtained with a nonspatial (e.g., oral) response. We suggest that the entire pattern of performance might reverse if, say, the subject's response consisted of low-pitched and high-pitched vocalizations (perhaps uttering the vowels $/ o /$ and $/ \mathrm{i} /$ ). In support of this hypothesis are studies suggesting that at least part of the Stroop effect may be attributed to the compatibility between the processing of the stimulus and the mode of response (McClain, 1983a, 1983b; Redding \& Gerjets, 1977; Virzi \& Egeth, 1985).

McClain (1983a), for instance, found a smaller colorword Stroop effect when subjects responded by pressing buttons labeled with the color names instead of naming colors orally. Further, interference was absent when the subjects pressed buttons labeled with color patches. Correspondingly, with auditory words and pitches, a Stroop effect appeared only when the irrelevant dimension and the response mode were compatible (pitch-hum, wordverbal, word-button) and not when they differed (pitchverbal, pitch-button, word-hum) (McClain, 1983b). Yet compatibility may not suffice to explain asymmetric Stroop effects, given that such effects are small, but not absent, when the stimulus dimension and mode of response are incompatible. Moreover, in one of the several analogues developed to Stroop effects, the "flanker" task (Eriksen \& Eriksen, 1974; Flowers \& Wilcox, 1982), relevant letters (or words, in later versions) appear in welldesignated locations, simultaneously with irrelevant letters (i.e., "noise") presented in irrelevant locations. Typically, RT to the relevant stimuli increases when the relevant and irrelevant stimuli differ (see Yeh \& Eriksen, 1984). Because in flanker tasks, both the relevant and irrelevant stimuli belong to the same dimension, interference effects emerging in such tasks probably depend on specific stimulus-response associations rather than the relation between dimensions and response modes.

\section{Role of Stimulus Difference}

Asymmetry is also evident in the ways that pitch differences and position differences affected performance. One might expect that the smaller the difference between the values on the dimension being classified, the more vulnerable the classification would be to interference by orthogonal variation in the irrelevant stimulus, and further, that this interference would be greater when the difference in the values on the irrelevant stimulus was large. Although this outcome did obtain when subjects classified by pitch, classification by visual position was unaffected by either the values of spatial position (i.e., the relevant dimension) or the values of pitch (i.e., the irrelevant dimension).

Why are more similar pairs of tones (assuming, as seems reasonable, that similarity is inversely related to $\Delta_{\mathrm{pi}}$ ) classified more slowly than dissimilar pairs of tones? Given that RT reflects the time needed to encode each tone as "high" or "low," it is likely that speed of response indicates the time needed to accrue sufficient information to reach a criterial level (see, e.g., Grice, 1968, Petrusic, 1992, and Link, 1992, as examples of accrual models of choice RT). By this view, faster RTs reflect faster encoding or accrual of relevant information. Nevertheless, it is also possible that all tones are encoded at more or less the same rate, but that greater variation in stimulus frequency (greater $\Delta_{\mathrm{pi}}$ ) makes each presentation of a tone more salient, and therefore more arousing, thereby evoking quicker response. If so, one would predict a phenomenon similar to "inhibition of return" (Posner, Rafal, Choate, \& Vaughan, 1985): Salience and arousal should be smaller, and hence RT should be greater, with repetition of the same signal frequency on successive trials, but the difference between RT to Fre- 
quency 1 following Frequency 1 and RT to Frequency 1 following Frequency 2 should be much greater when $\Delta_{\mathrm{pi}}$ is great than when $\Delta_{\mathrm{pi}}$ is small.

\section{Garner Interference and Effects of Congruence}

That visual-auditory asymmetries reveal themselves in both Garner interference and congruence raises the question, What processes underlie the asymmetries? Recall that Garner interference refers to an overall impairment in performance due to variation in the values on an irrelevant dimension or in an irrelevant stimulus, regardless of the specific pairing of the values. Congruence effects, however, are defined on particular stimulus-stimulus pairings and may be related to Stroop effects, which have been considered to derive from incongruence of signals within each trial (see Pomerantz et al., 1989). The Stroop effect is commonly called an impairment (usually slowdown) in responding to complex stimuli containing conflicting information, in comparison with responding to neutral stimuli varying only in the attended dimension (Pieters, 1981; Shor, 1975; Stroop, 1935). Although Stroop used only color words with colored ink, the hundreds of subsequent studies have demonstrated analogous effects with other dimensions and modalities, such as visual combinations of pictureword (Lupker \& Katz, 1982; Rosinki, Golinkoff, \& Kukish, 1975), or word -arrow (Shor, 1970), as well as auditory combinations of word-pitch (Hamers \& Lambert, 1972; Melara \& Marks, 1990c).

Although both Stroop effects and Garner interference are considered measures of dimensional interaction, they are sometimes believed to involve different processes (Pomerantz et al., 1989). Recent models of Stroop effects (Cohen, Dunbar, McClelland, 1990; Logan, 1980) concentrate on attentional processes in perceiving and analyzing simultaneously presented contradictory information. That is, the Stroop impairment is thought to derive from content-dependent intratrial interference. In contrast, Garner interference is defined and computed as the impairment in performance evoked by random variation (and thus unpredictability), as compared with constant presentation, of the irrelevant stimulus. Because both congruent and incongruent combinations of the relevant and irrelevant stimuli are averaged in orthogonal tasks, the increase in RT in these tasks is considered to stem from the intertrial irregularity of the relevantirrelevant stimuli combinations, and not from the specific intrastimulus content relations.

Garner interference and Stroop effects may, however, involve common processes. As in other studies (e.g., Melara \& O'Brien, 1987), the congruence effects found here in judgments of pitch were evident only in orthogonal and correlated tasks but were absent in baseline conditions. That is, congruence seems to emerge on the basis of relative values on two dimensions (see Clark \& Brownell, 1975). Congruence effects may be due not only to the existence of incongruent perceptual relations between values on two dimensions but also to the shifts between congruent and incongruent pairings over trials, shifts that may act to prevent habituation to the irrelevant stimulus, as presumably also occurs in the generation of Garner interference. Consequently, Garner interference and congruence effects should be closely related. Supporting this reasoning is our finding that the magnitude of the pitch difference had similar effects on Garner interference and congruence effects. Other support is provided by studies showing that Stroop effects are always accompanied by Garner interference, though Garner interference need not be accompanied by Stroop effects (see Pomerantz et al., 1989). It should be noted, of course, that Stroop or congruence effects require some correspondence between dimensions, whereas Garner interference does not.

\section{REFERENCES}

Ashby, F. G., \& MADDox, W. T. (1994). A response time theory of separability and integrality in speeded classification. Journal of Mathematical Psychology, 38, 423-466.

Callaghan, T. C., Lasaga, M. I., \& Garner, W. R. (1986). Visual texture segregation based on orientation and hue. Perception \& Psychophysics, 39, 32-38.

Carrell, T. D., Smith, L. B., \& Pisoni, D. B. (1981). Some perceptual dependencies in speeded classification of vowel color and pitch. Perception \& Psychophysics, 29, 1-10.

Clark, H. H., \& BrownelL, H. H. (1975). Judging up and down. Journal of Experimental Psychology: Human Perception \& Performance, 1, 339-352.

Cohen, J. D., Dunbar, K., \& McClelland, J. L. (1990). On the control of automatic processes: A parallel distributed processing account of the Stroop effect. Psychological Review, 97, 332-361.

Colavita, F. B. (1974). Human sensory dominance. Perception \& Psychophysics, 16, 409-412.

Colavita, F. B., Tomko, R., \& Weisberg, D. (1976). Visual prepotency and eye orientation. Bulletin of the Psychonomic Society, 8, 25-26.

Colavita, F. B., \& Weisberg, D. (1979). A further investigation of visual dominance. Perception \& Psychophysics, 25, 345-347.

Egeth, H. E., \& Sager, L. C. (1977). On the locus of visual dominance. Perception \& Psychophysics, 22, 77-86.

EriksEn, B. A., \& Eriksen, C. W. (1974). Effects of noise letters upon the identification of a target letter in a nonsearch task. Perception \& Psychophysics, 16, 143-149.

Flowers, J. H., \& Wilcox, N. (1982). The effect of flanking context on visual classification: The joint contribution of interactions at different processing levels. Perception \& Psychophysics, 32, 581-591.

Foard, C. F., \& Kemler Nelson, D. G. (1984). Holistic and analytic modes of processing: The multiple determinants of perceptual analysis. Journal of Experimental Psychology: General, 113, 94-111.

GARNER, W. R. (1974). The processing of information and structure. Potomac, MD: Erlbaum.

Garner, W. R. (1976). Interaction of stimulus dimensions in concept and choice processes. Cognitive Psychology, 8, 98-123.

Garner, W. R., \& Felfoldy, G. L. (1970). Integrality of stimulus dimensions in various types of information processing. Cognitive Psychology, 1, 225-241.

Grice, G. R. (1968). Stimulus intensity and response evocation. Psychological Review, 75, 359-373.

Hamers, J. F., \& LAMBERT, W. E. (1972). Bilingual interdependencies in auditory perception. Journal of Verbal Learning \& Verbal Behavior, 11, 303-310.

Haussmann, R. E. (1992). Tachistoscopic presentation and millisecond timing on the IBM PC/XT/AT and PS/2: A Turbo Pascal unit to provide general-purpose routines for CGA, Hercules, EGA, and VGA monitors. Behavior Research Methods, Instruments, \& Computers, 24, 303-310. 
Kornblum, S., Hasbroucq, T., \& Osman, A. (1990). Dimensional overlap: Cognitive basis for stimulus-response compatibility-A model and taxonomy. Psychological Review, 97, 253-270.

LiNK, S. W. (1992). The wave theory of difference and similarity. Hillsdale, NJ: Erlbaum.

Lockhead, G. R. (1972). Processing dimensional stimuli: A note. Psychological Review, 79, 410-419.

LOCKHEAD, G. R. (1979). Holistic versus analytic process models: A reply. Journal of Experimental Psychology: Human Perception \& Performance, 5, 746-755.

Logan, G. D. (1980). Attention and automaticity in Stroop and priming tasks: Theory and data. Cognitive Psychology, 12, 523-553.

LuPKER, S. J., \& KaTZ, A. N. (1982). Can automatic picture processing influence word judgments? Journal of Experimental Psychology: Learning, Memory, \& Cognition, 8, 418-434.

MARKs, L. E. (1974). On associations of light and sound: The mediation of brightness, pitch, and loudness. American Journal of Psychology, 87, 173-188.

MARKs, L. E. (1975). On colored-hearing synesthesia: Cross-modal translations of sensory dimensions. Psychological Bulletin, 82, 303-331.

MARKs, L. E. (1978). The unity of senses: Interrelations among the modalities. New York: Academic Press.

MARKs, L. E. (1982a). Bright sneezes and dark coughs, loud sunlight and soft moonlight. Journal of Experimental Psychology: Human Perception \& Performance, 8, 177-193.

MaRKS, L. E. (1982b). Synesthetic perception and poetic metaphor. Journal of Experimental Psychology: Human Perception \& Performance, 8, 15-23.

MarKs, L. E. (1987). On cross-modal similarity: Auditory-visual interactions in speeded discrimination. Journal of Experimental Psychology: Human Perception \& Performance, 13, 384-394.

MARKs, L. E. (1988). Magnitude estimation and sensory matching. Perception \& Psychophysics, 43, 511-525.

MARKS, L. E. (1989). On cross-modal similarity: The perceptual structure of pitch, loudness, and brightness. Journal of Experimental Psychology: Human Perception \& Performance, 15, 419-433.

MaRKS, L. E. (1992). The slippery context effect in psychophysics: Intensive, extensive, and qualitative continua. Perception \& Psychophysics, 51, 187-198.

Marks, L. E. (1994, July). Representations of space: Encoding and recoding. Paper presented at Attention and Performance XVI, Kyoto, Japan.

Marks, L. E., Hammeal, R. J., \& Bornstein, M. H. (1987). Perceiving similarity and comprehending metaphor. Monographs of the Society for Research in Child Development, 52(1, Series No. 251), $1-93$.

MCCLAIN, L. (1983a). Effects of response type and set size on Stroop color-word performance. Perceptual \& Motor Skills, 56, 735-743.

McClain, L. (1983b). Stimulus-response compatibility affects auditory Stroop interference. Perception \& Psychophysics, 33, 266-270.

Melara, R. D. (1989). Dimensional interaction between color and pitch. Journal of Experimental Psychology: Human Perception \& Performance, 115, 212-231.

Melara, R. D., \& MARKS, L. E. (1990a). Dimensional interaction in language processing: Investigating directions and levels of crosstalk Journal of Experimenial Psychology: Learning, Memory, \& Cognition, 16, 539-554.

Melara, R. D., \& Marks, L. E. (1990b). Interaction among auditory dimensions: Timbre, pitch, and loudness. Perception \& Psychophysics, 48, 169-178.

MELARA, R. D., \& Marks, L. E. (1990c). Processes underlying dimensional interactions: Correspondences between linguistic and nonlinguistic dimensions. Memory \& Cognition, 18, 477-495.

Mel.ara, R. D., Marks, L. E., \& Lesko, K. E. (1992). Optional processes in similarity judgments. Perception \& Psychophysics, 51, 123-133.

Melara, R. D., Marks, L. E., \& Potts, B. C. (1993). Early-holistic processing or dimensional similarity? Journal of Experimental Psychology: Human Perception \& Performance, 19, 1114-1120.

Melara, R. D., \& MounTs, J. R. W. (1994). Contextual influences on interactive processing: Effects of discriminability, quantity, and uncertainty. Perception \& Psychophysics, 56, 73-90.

Melara, R. D., \& O'Brien, T. P. (1987). Interaction between synes- thetically corresponding dimensions. Journal of Experimental Psychology: General, 116, 323-336.

Mullennix, J. W., \& Pisoni, D. B. (1990). Stimulus variability and processing dependencies in speech perception. Perception \& Psychophysics, 47, 379-390.

Petrusic, W. M. (1992). Semantic effects and theories of the comparison process. Journal of Experimental Psychology: Human Perception \& Performance, 18, 962-986.

Pieters, J. M. (1981). Ear asymmetry in an auditory spatial Stroop task as a function of handedness. Cortex, 17, 369-379.

Pomerantz, J. R. (1983). Global and local precedence: Selective attention in form and motion perception. Journal of Experimental Psychology: General, 112, 515-540.

Pomerantz. J. R. (1986). Visual form perception: An overview. In E. C. Schwab \& H. C. Busbaum (Eds.), Pattern recognition by humans and machines: Visual perception (pp. 1-30). New York: Academic Press.

Pomerantz, J. R., Pristach, E. A., \& Carson, C. E. ( 1989). Attention and object perception. In E. B. Shepp \& S. Ballesteros (Eds.), $O b-$ ject perception: Structure and process (pp. 53-89). Hillsdale, NJ: Erlbaum.

POSNER, M. I. (1964). Information reduction in the analysis of sequential tasks. Psychological Review, 71, 491-504.

Posner, M. I., Nissen, M. J., \& Klein, R. M. (1976). Visual dominance: An information-processing account of its origins and significance. Psychological Review, 83, 157-171.

Posner, M. I., Rafal, R. D., Choate, L. S., \& Vaughan, J. (1985). Inhibition of return: Neural basis and function. Cognitive Neuropsychology, 2, 211-228

Redding, G. M., \& GerJets, D. A. (1977). Stroop effect: Interference and facilitation with verbal and manual responses. Perceptual \& Motor Skills, 45, 11-17.

REPP, B., \& LiN, H. (1990). Integration of segmental and tonal information in speech perception: A cross-linguistic study. Journal of Phonetics, 18, 481-495.

RoFfler, S. K., \& BUTLER, R. A. (1968). Localization of tonal stimuli in the vertical plane. Journal of the Acoustical Society of America. 43, $1260-1266$

Rosinki, R. R., GolinkofF, R. M., \& Kukish, K. S. (1975). Automatic semantic processing in a picture-word interference task. Child Development, 46, 247-253.

SHEPARD, R. N. (1964). Attention and the metric structure of the stimulus space. Journal of Mathematical Psychology, 1, 54-87.

SHOR, R. E. (1970). The processing of conceptual information on spatial directions from pictorial and linguistic symbols. Acta Psychologica, 32, 346-365.

SHoR, R. E. (1975). An auditory analog of the Stroop test. Journal of General Psychology, 93, 281-288.

Smith, J. D., \& Kemler Nelson, D. G. (1984). Overall similarity in adults' classification: The child in all of us. Journal of Experimental Psychology: General, 113, 137-159.

Stroop, J. R. (1935). Studies of interference in serial verbal reactions. Journal of Experimental Psychology, 18, 643-662.

VICKERS, D. (1970). Evidence for an accumulator model of psychophysical discrimination. Ergonomics, 13, 37-58.

VIRZI, R. A., \& EGETH, H. E. (1985). Toward a translational model of Stroop interference. Memory \& Cognition, 13, 304-319.

YEH, Y.-Y., \& ERIKSEN, C. W. (1984). Name codes and features in the discrimination of letter forms. Perception \& Psychophysics, 36, 225-233.

\section{NOTE}

1. We tested the possibility of practice effects on Garner interference by applying MANOVAs to interference scores (orthogonal minus baseline RTs) for pitch judgments and position judgments using the session's order of the conditions $(1-5)$ as the within-subjects variable Neither pitch judgments nor position judgments showed a practice ef fect $[F(4,44)=.87$ and 1.90 , respectively $]$

(Manuscript received October 6, 1994; revision accepted for publication March 5, 1995.) 